\title{
O pano verde da ilusão: 0 imaginário e o jogo ilegal
}

\section{Elza Kioko Nakayama Nenoki do Couto}

Doutora; Universidade Federal de Goiás, Goiânia, GO, Brasil

kiokoelza@gmail.com

\section{Anderson Nowogrodzki da Silva}

Mestre; Universidade de Brasília, Brasília, DF, Brasil

a.nowogrodzki2@gmail.com

\section{Resumo}

A linguagem dos depoimentos de jogadores compulsivos é suscetível de explicar a relação simbólica deles com o mundo. A partir dessa perspectiva, examinam-se as imagens míticas que podem ser depreendidas de significantes linguísticos. Por meio de depoimentos de jogadores compulsivos coletados na internet, reflete-se sobre o trajeto antropológico do imaginário do jogador de jogos ilegais e seu mito. Os pressupostos teóricos deste trabalho têm por base a antropologia do imaginário de Gilbert Durand, segundo a qual a relação do sujeito com o objeto pode ser representada por uma imagem. Dessa forma, configura-se uma pesquisa qualitativa, baseada no método hipotético-dedutivo, a fim de interpretar e analisar dados que permitam alcançar um valor de verdade. Jogar com o acaso ou com as probabilidades pode ter o sentido simbólico de negociar com o destino. Poder controlar o próprio destino é possível apenas aos deuses, os seres imortais. Portanto, o espaço do jogo ilegal é um espaço profano em contato com a esfera do sagrado, que possibilita a ilusão de jogar com o destino. Nesse sentido, o jogo pode ser visto como uma experiência mítica.

\section{Palavras-chave}

Antropologia do Imaginário. Mito. Regimes. Jogos ilegais.

\section{Introdução}

Etimologicamente, a palavra jogo deriva do termo latino jocus e é utilizada para significar alguma atividade física, mental ou de entretenimento próprio do sujeito para comunicar sua presença em algum grupo social. No plano cultural, constitui a atividade física, intelectual e emocional que possibilita ao indivíduo desenvolver habilidades que o 
auxiliem a corresponder às exigências desse grupo social. Mesmo que seja pelo tempo fugaz de sua atividade, o jogo sempre corresponde ao sentimento de pertença ao grupo, assim como o modo geral da possibilidade de se definir pessoas ou grupos como vencedores ou perdedores. Entretanto, a sorte de ganhar ou perder não depende apenas da habilidade do jogador, mas de uma casualidade natural, firmada em possibilidades matemáticas como ocorre, por exemplo, nos chamados "jogos de azar".

O que marcava os bons costumes nas décadas do último século apoiava-se, geralmente, em preceitos religiosos e cívicos. Atualmente, a população confronta-se incessante e profundamente com o mercantilismo, expandido, sobretudo, pela propaganda presente nas inúmeras e diversas formas de comunicação. A televisão, o rádio, os cartazes, as revistas e os jornais exploram insistentemente formas de comunicação elaboradas com imagens e dizeres extremamente sugestivos de modo a despertar o desejo que fatalmente conduz ao consumo. Como a avaliação das pessoas é programada, primeiro ou quase sempre, pela aparência de sua imagem ou estilo de vida, é comum tanto mulheres como homens voltarem-se para o jogo de azar, imaginando que pode lhes fornecer a possibilidade de enriquecer e viver uma vida melhor.

O jogo foi proibido no Brasil em 1946, pelo presidente Eurico Gaspar Dutra, que determinou, segundo consta, à insistência de sua esposa, o fechamento dos cassinos, instalados quase sempre nos grandes hotéis. Desde o início da década de 1990, porém, a grande motivação para o consumo de bens tem aumentado a inclinação para o jogo, como uma forma de possibilitar de modo instantâneo o enriquecimento de qualquer pessoa. Entretanto, observa-se que é possível surgirem jogadores patológicos.

Para muitas pessoas, a proibição do jogo, entretanto, confronta-se com o princípio da liberdade pessoal. Por essa razão, ultimamente, têm surgido pareceres contra a ilegalidade desses jogos, partindo da pressuposição de que a sua legalização pode oferecer rentabilidade aos cofres públicos por meio da arrecadação de impostos ou de multas e, assim, constituir uma modalidade financeira que auxilie ou resolva crises econômicas também no plano governamental.

Reconhece-se, facilmente, que, no Brasil, o número de pessoas que jogam na loteria federal, no jogo do bicho ou, ainda, nas mesas (baralho), em locais ou situações particulares, é expressivo, atingindo os mais diversos grupos de indivíduos. Entretanto, a possível legalização de jogos, assim como sua regulamentação, pode possibilitar às casas de apostas a prática de outros crimes, como corrupção e lavagem de dinheiro, além da criação de 
problemas financeiros, sociais e familiares a muitos jogadores. Desse modo, destaca-se não apenas a fragilidade dos jogadores - os quais muitas vezes põem em risco toda a sua estrutura financeira, familiar e social - mas, sobretudo, a importância de se determinar outras formas de vencer o desejo de jogar.

O drama vivido por jogadores compulsivos mais uma vez foi retratado na televisão, pela Rede Globo, no enredo da novela Insensato coração, desenvolvido em 2011. 0 jornalista Kléber Damasceno, interpretado pelo ator Cássio Gabus Mendes, destacou a vida de uma personagem que, estando sem recursos para apostar, roubou dinheiro de sua própria faxineira (INSENSATO..., 2011). Em 2017, a novela A força do querer, da Rede Globo, focaliza a personagem Silvana, interpretada por Lília Cabral, que se envolve de corpo e alma na dependência do jogo (A FORÇA..., 2017). A abordagem desse vício em novelas retrata a realidade de milhares de brasileiros e possibilita examinar como se desenvolve o trajeto antropológico do imaginário do praticante desses jogos ilegais, assim como a construção de seu mito.

Jogar com o acaso ou com probabilidades de êxito pode ter o sentido simbólico de se negociar com o destino, assim como acreditar que o controle do próprio destino é algo possível apenas a deuses ou a seres imortais. Desse ponto de vista, percebe-se que o espaço no jogo corresponde a um ambiente profano no qual o sagrado possibilita uma ilusão. Nesse sentido, o jogo pode ser visto como uma experiência mítica.

\section{Imagens e imaginário à luz da antropologia}

Antônio Damásio (2000), em sua obra $O$ mistério da consciência, considera que as imagens surgem do processo interativo do sistema cerebral criativo e imaginante com o meio físico, biológico e social do indivíduo. Nesse processo, julga que "As imagens originamse de padrões ou mapas neurais, formados em populações de células nervosas, ou neurônios, que constituem circuitos ou redes." (DAMÁSIO, 2000, p. 407). É segundo essa perspectiva que se deve entender a função e a atividade da imaginação, razão que motiva tanto Gaston Bachelard (1996), como Gilbert Durand (1989), a descrevê-la não apenas como uma faculdade, mas como a atividade dinâmica de o homem (de)formar as imagens criadas pela percepção, pontuando uma espécie de contrato entre psiquismo e suporte biológico, contrato que lhe possibilitará atuar no meio em que vive. 
Ao dar continuidade às pesquisas de Bachelard, na década de 1960, Durand (1982) precisa o sentido do que denomina imaginário, distinguindo este termo do que se entende como imaginação e explicitando que, se esta é descrita como a faculdade de perceber, reproduzir ou criar imagens, aquela é explicitada como a maneira como tal faculdade é operacionalizada. Assim, no exame da operacionalização das imagens, reconhece o que chama de "trajeto antropológico do imaginário", ou seja, as modalidades que o ser humano descobre, percorre, assimila e vivifica continuamente ao se confrontar com sua condição de comunicador. Tal fato ocorre porque, como afirmam Gilles Deleuze e Felix Guattari (2003, p. 259), nós, falantes, "pedimos somente um pouco de ordem para nos proteger do caos". Entende-se, portanto, que o pensamento racionalizado se fundamenta na existência de imagens, concedendo ao imaginário a função euforizante.

Para que se possa entender a dinâmica do imaginário é preciso compreender sua projeção na sociedade por meio de imperativos biopsicopulsionais que, aliados às intimações do meio social, permitem ao sujeito escolher e dinamizar certas imagens, dando contornos a uma perspectiva individualizada da realidade, modificando o modo como se atua sobre o mundo, sobre o tempo e sobre o espaço.

Ao trazer à tona o conceito de "trajeto antropológico" como forma de organização do imaginário, Durand (1989) especifica sua dinâmica, demonstrando as configurações da estrutura enquanto processo contínuo que legitima a ideia de que a imagem se apresenta como matriz do pensamento racionalizado.

Por essa razão, a Escola de Leningrado, formada na década de 1920 por um grupo de pesquisadores russos liderados por Wladimir Betcherev, passou a se dedicar, sistematicamente, ao estudo do aparelho nervoso do homem, dando prosseguimento às pesquisas desenvolvidas por Ivan Pavlov, no campo da psicofisiologia de animais.

A expansão desses estudos motivou a pesquisa a focalizar o sistema funcional do recém-nascido humano e, centrando-se em sua sensorialidade motora, comprovar que as respostas cerebrais a estímulos originados do meio ambiente não têm o mesmo tipo e grau de atualização, pois alguns deles coordenam ou inibem outros e o fazem evidenciando diferentes níveis de dominância de um sobre o outro.

A observação da intensidade desses níveis incentivou Durand (1989) a classificar tais reações como "dominantes reflexas" e, partindo das observações feitas, inicialmente com os animais, a concluir que a primeira dominante reflexa é o posicionamento vertical, reflexo voluntário do recém-nascido para levantar-se; a segunda dominante é a deglutição, 
já que todo recém-nascido possui naturalmente os reflexos de sucção labial. 0 estudo dessas duas dominantes, seja em animais ou seres humanos, foi complementado por observações que indicam uma terceira dominante: a copulação. É esta que, apesar de ter sido focalizada somente em animal adulto, é considerada uma estrutura psicofilológica inata nos humanos.

Para criar sua hipótese e construir sua teoria, Durand partiu das pesquisas da Escola de Leningrado. Tais estudos possibilitaram-lhe concluir que existe uma estreita concomitância entre os gestos do corpo, os centros nervosos e as representações simbólicas. Assim, amplia o estudo das imagens, pesquisando e descrevendo suas relações com a mitologia, com a literatura e as artes plásticas em diversas culturas, a fim de classificá-las, após cuidadoso exame, no plano diacrônico e sincrônico da simbologia. A observação dessa classificação motivou o exame desses planos em busca de uma relação mais interativa com os regimes de imagens, a fim de reconhecer e classificar a força semântica do processo cognitivo e o grau da forma comunicativa do falante. Tal exame possibilitou perceber melhor a construção do sentido discursivo e compreender melhor a feição particular de seu sujeito:

a) postural ou ascensional - quando o discurso se constitui de matérias luminosas e visuais, providas de técnicas de separação e de purificação, cujos principais símbolos são as armas, as flechas, as facas, as palavras, os gritos, as cores berrantes, as torres e colunas, ou qualquer objeto ou ação que evidencie formas tanto penetrantes como ascendentes, assim como brilhantes ou enfáticas;

b) digestiva ou homogeneizante - quando o discurso requer matérias que implicam o sentido de continência, como a água e a terra, ou suscitam o sentido de instrumentos protetores, como a casa, a caverna, as embarcações, ou utensílios, sejam taças, cofres, caixas ou qualquer espaço continente com forma côncava ou profunda, mas sempre relacionando formas que apontem os simbolismos ou devaneios relativos à ilusão de abrigo;

c) sexual, cíclica ou rítmica - quando atualiza, seja nos movimentos cíclicos das estações, da vida, do florescimento, ou dos movimentos repetitivos de formas técnicas, como o relógio e algumas máquinas; seja em atividades humanas expressivas, como a reprodução ou a repetição criativa de algo, como a música, a dança, a pintura, a escultura ou a recitação.

Historicamente, a teoria durandiana apontou, a princípio, dois regimes: as imagens do primeiro (referentes à ascensão) constituem as imagens heroicas e compõem o regime 
denominado diurno; as do segundo (referentes à deglutição) formam as imagens místicas e constituem o regime chamado noturno.

Entretanto, ao rever cuidadosamente o desenvolvimento dessas classificações, Durand (1995) reconhece um terceiro conjunto, ou seja, as imagens reveladoras de uma síntese, agregadas, até então, ao regime noturno. Em um primeiro momento, ele fixara uma relação íntima entre a deglutição e a copulação, entretanto, em sua obra Mito, símbolo $e$ mitodologia (1982), apresenta claramente novas posições: afirma que hoje chamaria modalidades o que chamara, a princípio, estruturas de representação, e que não incluiria mais a estrutura que denominara sintética no regime noturno, pois esta, diferenciando-se da que é chamada mística, recebe uma configuração particular, devendo, por conseguinte, constituir um regime à parte.

Tal posição motivou M. T. Strôngoli (2000) a considerar as imagens sintéticas formadoras realmente de um regime próprio, ao qual sugere chamar crepuscular e a reorganizar, consequentemente, as estruturas ou modalidades de imagens não mais em dois, mas em três regimes. A configuração desses três regimes, seus subgrupos e a denominação do terceiro deles, foi discutida e aprovada por Durand, assim como pelos estudiosos presentes no Coloque Internacional de l'imaginaire, realizado em Cerisy, França, em julho de 1991. Tais considerações incentivaram um novo olhar sobre o imaginário, assim como novas e mais claras cogitações sobre os regimes, como se verá em seguida.

0 regime diurno contém as imagens que figurativizam a atitude heroica para vencer qualquer situação, seja de angústia, de medo ou de adversidade, mas implicando sempre o sentido e a percepção do confronto, por meio do uso de qualquer arma como: palavras, gestos, gritos, ou agressões que evoquem a figura exigente e autoritária do Pai ou da Lei.

O regime noturno, ao contrário, busca imagens de conciliação e harmonização do indivíduo com o outro, com a natureza, a tradição, a arte e o humanismo. Em geral, no plano da expressão, esse regime costuma ser repetitivo, pormenorizado, expressivo e centrado em formas detalhadas que apelem para divagações ou sentimentalismo.

O regime crepuscular inclina-se para o uso de imagens que estabelecem posições polarizadas, nas quais se destacam o certo e o errado, o bem e o mal, assim como as formas que indicam a sistematização de visões de mundo históricas, filosóficas ou conscientes. De um modo geral, inclina-se para as perspectivas do futuro e o sentido da possibilidade ou da ilusão de, pondo ordem nas estruturas de imagens, conseguir vencer os problemas e alcançar o progresso. 
Compreende-se, assim e mais facilmente, que o sujeito no regime diurno pretende vencer com armas na mão: (argumentos, lógica, ironia, força, regras e precisão); no regime noturno, ao contrário, com sensibilidade (sentimentos, tradição, emoção, associações e repeticões); finalmente, no regime crepuscular, com criatividade (sistemas ou pesquisa, seja por meio da filosofia, religião, ciências ou história).

Convém, contudo, destacar que as atividades lúdicas não se restringem ao jogo e à brincadeira, incluem também atividades que possibilitam momentos de prazer, integração, ou reconhecimento de determinados valores. Tais sensações costumam propiciar uma experiência de plenitude, na qual é possível se envolver por inteiro, de modo flexível e bem vivido. A fruição costuma ser povoada pela imaginação e pelos sonhos que se articulam ou se manifestam simbolicamente.

\section{Jogo de azar, imagens, imaginário e mito}

Considerando as dimensões substantivas dos movimentos desenvolvidos e articulados no interior da mente de jogadores, observa-se que o jogo lúdico pode ser compreendido como instaurador de espaços dinâmicos no imaginário, nos quais o contato entre o universo interior e o meio exterior do jogador pode deflagrar imagens que se renovam, se amplificam ou se transformam, imaginariamente, em vida e morte. Além disso, é comum acrescentar-se ao ato de jogar, certa ludicidade. Esse termo refere-se ao processo interno de vivência ou à consciência de quem vive experiências lúdicas. No Brasil, não é permitida a construção de cassinos e tal fato leva a perguntar: que tipo de ludicidade move os jogadores compulsivos em países como a França, por exemplo, onde existem cassinos abertos ofertando todo tipo de jogos? É sobre esses jogos que se pretende discorrer.

A vida cotidiana do ser humano é construída de eventos que necessitam de um lugar e de um tempo para acontecer. Um evento, nesse sentido, mais do que um simples acontecimento, é um "instante do tempo", assim como um "ponto do espaço". São estes que configuram as formas da experiência humana, as quais, com certeza, implicam a possibilidade de o sujeito assumir sua condição de sujeito, ou seja, de um Eu. Desse ponto de vista, reconhece-se que o evento não é apenas um simples fator de localização ou de temporalidade: nele se manifestam as imagens de pertença com as quais o sujeito se confronta em vários planos e configurações, como seres, objetos, valores, emoções, circunstâncias, intimidades e consciência. 
É assim que se entende o mundo dos jogos: um espaço livre, em que o jogador tem a capacidade de simbolizar, dar ou usufruir o sentido não apenas de coisas, mas de fatos, situações, ações e sentimentos pessoais. 0 jogo faculta a manifestação de espaços íntimos e possibilita ao jogador assumir ou criar funções simbólicas, assim como a "[...] ilusão de um saber, visto que é próprio do símbolo configurar a essência e revelar o que é indizível." (DURAND, 1995, p.11). É a condição de simbolizador que livra o jogador das pressões sociais, da subserviência ao Outro, estendendo o direito à interioridade pessoal. 0 mundo do jogo é, portanto, o lugar onde o sujeito/jogador pode dispor de liberdade e fazer o investimento simbólico que deseja ou necessita. É no interior de sua intimidade imaginária, que ele extrai elementos que favorecem sua capacidade de recriar o mundo em relação a si mesmo e ao Outro, pois a imaginação, como assegura Durand (1982), não apenas recria fatos, coisas e dramas: ela, verdadeiramente, inventa uma vida nova ou uma vida paralela.

Nesse caso, é preciso ter presente que o jogo resulta de um ato concreto e pressupõe, naturalmente, um agente, ou melhor, um sujeito que revela suas condições de ser e agir, fato que sustenta a consideração de que não há ação sem imaginação. 0 que dá ao jogador o poder não apenas de apropriar-se de um espaço, a fim de torná-lo seu, mas de introduzir por meio dele, o livre jogo do "eu quero", "eu devo", "eu posso". No jogo, a imaginação não é simplesmente uma fantasia, pois o sujeito cria um verdadeiro espaço de representação, conduzindo ao seu processo imaginativo. Esse processo dá ao jogador o poder de apropriarse de um espaço para torná-lo seu e, por meio dele, introduzir as posições: eu quero, eu devo, eи posso.

Justifica-se, assim, centrar-se na obra ou nos julgamentos de Durand e examinar atentamente o que ele chama de "tradição intelectualista", ou seja, a sensação percebida pela imaginação como uma faculdade passiva de reproduzir objetos ou, simplesmente, meras cópias de objetos reais. Ao exercitar a imaginação, pontuando a existência e o sentido de junção entre os gestos inconscientes e as representações, reconhece-se que a imaginação e o imaginário não criam apenas imagens, mas organizam-nas dinamicamente, reformando sensações e percepções, tornando-as a base de toda a vida psíquica, como se comprova em texto do portal EBC, que explica o tema jogos (MELITO, 2016, doc. não paginado):

PORTAL - Quando você começou a jogar?

AR - Há uns 20 anos, e o porquê até hoje não sei. Fui por convite de uma conhecida, por curiosidade, comecei a ganhar e, obviamente, me empolguei. Deixava minha filha na escola e não tinha o que fazer. 
Aí, comecei nas cartelinhas e não gostei, queria mais. Comecei a ir para o computador, com mais adrenalina. De lá, fui parar nas máquinas caçaníqueis e essa foi a minha perdição.

PORTAL - Qual era seu trabalho nessa época?

AR - Eu não trabalhava. Tinha um dinheiro disponível, cuidava da minha filha, vendia algumas roupas ou coisas assim. Não me sentia útil para a sociedade. Foi nesse momento de vazio que comecei a jogar. Junto com o jogo veio a ilusão de que estava ganhando. Mas nunca estava, você joga 100 e perde 500. Perdi carro, apartamento, minha filha e minha família.

A entrevistada parece encontrar, quando joga, um lugar na sociedade, pois acredita que o vazio que sente pode se ajustar à ilusão de ganhar ou de vencer no jogo. Assim, a ação de jogar é vista como um aprofundamento na própria condição humana, pois o jogador se encontra em um paradoxo fundamental: por um lado, compartilhar uma atividade própria da sociedade, satisfazendo as intimações do meio social; por outro lado, corresponder a seu anseio íntimo de prazer pessoal por meio do uso de adrenalina. Nessa aporia ou incerteza, o "eu" não opta por nenhuma das duas, ou seja: joga com o acaso na tentativa de que a solução seja oferecida por um "terceiro não determinável”, ou seja, o "tertio non datur" junguiniano.

Nos países em que o jogo é permitido, encontram-se cassinos em edifícios muitas vezes luxuosos e com salas aparelhadas para as várias modalidades de jogo. É o espaço apropriado para o exercício pessoal: eu devo, eu posso, eu sou, eu venço. 0 trajeto do jogador objetiva, claramente, chegar à vitória por meio de luta, mas esta não é uma tarefa vã. Ao contrário, o jogador capta uma imagem para torná-la sua e o espaço do jogo passa, facilmente, a ser o lugar das representações dos dramas humanos: os impasses do cotidiano, os dilemas da vida e da morte, a eterna busca do conhecimento ou da condição de poder ser útil a alguém. E se há um instrumento para a realização dessa tarefa, este só pode ser a imaginação, uma vez que cabe a ela, dinamizando o imaginário, conduzir o jogador para o mundo possível da ação.

Desse modo, é no imaginário que o jogador experimenta buscar e vivenciar seu poder, querer, saber e tornar suas as coisas do mundo. Trata-se da atitude ilusória de autopreservação e da aquisição de um poder sobre si próprio. É como se o jogador habitasse uma casa onde tudo é extremamente confortável, mas particular, ou seja: as bebidas e comidas são oferecidas inteiramente de graça, mas nela não se vê relógios ou janelas, pois o tempo é instaurado pelo jogo que possibilita ao jogador dar liberdade à sua imaginação, assim como ação a seu imaginário. 0 jogador enriquece, desse modo, sua vida interior de forma a poder desvencilhar-se das intimidações do dia a dia para, finalmente, projetar-se em 
outro tempo. Entretanto, esse outro tempo não existe, apenas lhe possibilita desfrutar do sentimento de pertença a outro mundo sem fronteira ou leis e, sobretudo, onde o tempo não existe.

Apesar dessas constatações sobre os jogos de azar, segundo Sutton-Smith (1986), a tecnologia dos brinquedos, sobretudo os modernos, possibilita o desenvolvimento de habilidades que auxiliam crianças e jovens a responderem melhor às exigências da sociedade, já que tais habilidades proporcionam, mesmo que seja pelo tempo fugaz de seu uso, o sentimento de pertença a determinado grupo. Desse modo, tais atividades ou distrações possibilitam crianças e jovens a assumirem a competência de consumidores de bens sociais, além de se prepararem emocionalmente para viverem dificuldades no mundo moderno.

O jogo de azar pode ser comparado à compulsão pela internet, pois o usuário, ao postar fotos nas redes digitais com o objetivo de receber notificações, produz conteúdos que funcionam como gatilhos para novas postagens. Em ambos os casos, o vício do jogo em si ou da imagem na internet configuram a poluição mental por meio de imagens viciantes: sejam as produzidas pelas redes digitais e/ou pelo imaginário do jogador. Ficam à mercê de vícios: os que se referem a apenas substâncias tóxicas, como nicotina, cocaína ou heroína, e os que implicam o consenso da possibilidade de vícios comportamentais. É para esse último grupo que a análise se volta, desvendando a relação do indivíduo com o jogo, centrando-se no exame de seus regimes de imagens e sua organização imaginativa:

a) observa-se o jogo na vida cotidiana, a fim de examinar a possibilidade de recusar ou de aceitar o chamado para os procedimentos cognitivos da semantização ou da resemantização das imagens que, polarizadas, refletem as estruturas de representação do imaginário humano, podendo ser marcadas pela oposição ou contradição, pela complementação ou harmonização e pela ciclicidade ou ritmo. A dinâmica dessas estruturas se alicerça sobre a ideia desenvolvida anteriormente de reflexos dominantes, conceituada por Durand como regimes;

b) constata-se um mentor e conhecem-se as formas do jogo;

c) frequenta-se o espaço onde costuma ocorrer o jogo e passar por vários testes, principalmente por aquele cuja recompensa pode ser a extrema;

d) filia-se definitivamente aos jogos e, possivelmente, muda-se a vida cotidiana;

e) imagina-se continuamente a cena das moedas caindo em grande quantidade na bandeja própria para o pagamento da premiação de uma "slot machine"; 
f) assume-se uma relação compulsiva: quando ganha $\rightarrow$ querer ganhar mais; quando perde $\rightarrow$ querer recuperar o que perdeu;

g) sabe-se que a dependência do jogo implica ou torna-se uma constante perseguição, por essa razão é considerada uma doença reconhecida pela Organização Mundial de Saúde, sendo considerada incurável, apesar de haver tratamento;

0 ato de jogar em máquinas ou cassinos pode transformar-se num ritual de vida e de morte, pois o imaginário do jogador não se limita à harmonia de uma vida cujo prêmio ou renda venha apenas do trabalho ou, às vezes, de uma herança. Ao contrário, volta-se para uma disforia da ilusão de acreditar que seu prêmio venha da sorte, não devido a seu mérito profissional, ou seja, a seu trabalho, qualquer que seja. Nesse caso, o jogo é visto não apenas como distração, mas como possível fonte de renda.

Do ponto de vista do imaginário do jogador, a atividade de jogar, sobretudo nos cassinos, coloca-se no regime diurno, pois se manifesta como a grande sorte, a força ou o deus heroico que dá poder ao homem, pois escolhe aleatoriamente o ganhador e não se deixa comandar ao premiar milagrosamente quando ninguém espera. Ao mesmo tempo, o jogo é repetitivo (toda a semana), pormenorizado (tem número ou nome) e centrado em formas detalhadas (tem categoria). Ao expressar características diurnas e noturnas, percebe-se que, na realidade, o jogo coloca-se no regime crepuscular, conjuga o sonho (noturno) à realidade (diurno). Conclui-se, portanto, que ele é crepuscular, pois contempla parte das imagens do noturno (desejo e esperança) e do diurno (perda do dinheiro do jogo e da ilusão).

\section{0 jogo e a vida social e profissional}

Mesmo quando o jogo não é visto como um problema, torna-se comum a pessoa deixar atividades sociais, antes valorizadas, para se dedicar a ele, perdendo muitas vezes o convívio com os amigos, com a família, ou comemorações de datas importantes. Toma-se, por exemplo, o caso de José: formado em química, na USP, e com curso intensivo de francês recém-concluído. Ganhou uma bolsa de estudos para examinar e aprender a composição, fabricação e conservação de vinhos na França. Lá chegando, apresentou-se à empresa na qual estagiaria, arranjou um pequeno espaço para morar e começou seu trabalho na empresa. Aprendeu logo os processos para reconhecer e classificar uvas e, em seguida, o que leva à diversificação das características modais de cada tipo de vinho, suas variações e 
particularidades e, principalmente, o prazer que eles dão. Em seguida, passou a convidar dois brasileiros, também estagiários em outras empresas, para jogar cartas e beber, todas as noites, o vinho que tirava diariamente do depósito de sua empresa. Essa situação não durou muito: a empresa de vinho, assim como seu vizinho, avisaram a polícia que, por sua vez, chamou o consulado brasileiro, para afirmar que José perdera o direito de trabalhar e morar na França.

É comum que as diversas mídias explorem a história de jogadores que se deixam seduzir pelo jogo. No site JornalI, encontra-se o artigo intitulado Vício invisível. As histórias de quem perdeu tudo o que tinha no casino (2012). O texto narra a vida de Helena, uma senhora que foi motivada a tentar a sorte em cassinos, sentou-se diante de uma máquina e ganhou um prêmio considerável. Foi o princípio do fim. Com diversos problemas em sua vida e já tendo tentado suicídio algumas vezes, Helena passou a frequentar a sala de jogos todos os dias, vendo no jogo uma forma de evasão. No espaço de poucos meses, não conseguia mais pagar as dívidas do banco. Acumulou uma dívida de mais de 60 mil euros. Na sequência desses fatos, foi instigada por seus filhos a participar das reuniões dos Jogadores Anônimos.

José começou a jogar durante a sequência de um divórcio aos 70 anos, deixando no espaço de apenas cinco anos mais de 80 mil euros no cassino. Durante esse tempo, valeu tudo: enganar fornecedores e clientes, colecionar créditos. Atualmente, afirma que está há dois anos em abstinência e frequentando toda semana as reuniões organizadas por um centro, cujo objetivo é auxiliar jogadores inventariados. Confessa, assim, que:

Toda a minha vida e todas as minhas energias eram canalizadas para a sala de jogos. Sei que sou uma pessoa emocionalmente complicada e jogar - a relação ganhar-perder - funcionava como uma espécie de anestesia para os problemas que estava a atravessar. Quando eu jogava, a solidão era imensa. Cada vez eu me afastava mais das pessoas, como se o vício me preenchesse (OS VÍCIOS..., 2013, doc. não paginado).

A vida profissional de jogadores é bastante diminuída porque eles, geralmente, despendem muito tempo em atividades voltadas ao jogo durante o período de trabalho, planejando os próximos passos, revendo resultados etc. Assim, Hélder, 37 anos, ainda está tentando recomeçar. Ele mesmo conta:

Eu estava numa posição em que lidava com muito dinheiro e acabei por desviar milhares de euros, que canalizava para o cassino. Logo eu, que nunca me imaginei a ser capaz de roubar o que quer que fosse (OS VÍCIOS..., 2013, doc. não paginado). 
Foi apanhado, julgado e condenado a uma pena de prisão quando chegou ao fundo do poço, gastando seu ordenado e mais 2 mil euros em apenas meia hora. Foi uma história que durou sete anos e acabou no banco dos réus quando confessou que perdeu por completo o controle das dívidas ao desviar dinheiro do local de trabalho.

Na vida familiar, a prática e "[...] o tempo gasto com o jogo faz com que os alicerces familiares fiquem estremecidos, seja por causa das perdas financeiras ou por conta da ausência do jogador. A família do jogador normalmente ameaça ou mesmo chega a abandoná-lo, com o objetivo de cessar esse comportamento." (O QUE É..., 2017, doc. não paginado), como confirma a declaração abaixo:

\begin{abstract}
O jogo começou a me dominar, mas eu não percebia, cheguei até a deixar minha neta sozinha em casa para jogar. Agora virou um mar de lama. Não tenho dinheiro, mas roubo cheque do meu marido, que está com câncer ósseo e me culpa pela doença. Tentei suicídio, minha amiga me salvou. Não sei como pude chegar nesse ponto. Ganhei 2 mil euros em outubro e na metade de novembro já tinha gastado tudo. Estou com problema de pressão alta, minha família não quer mais saber de mim. Já cheguei a gastar de 700 a 2.000 euros em um só dia. Eu odeio o jogo, mas sou impotente a ele. (TAVARES, 2004, doc. não paginado).
\end{abstract}

Esse é o depoimento de Simone, 65 anos, que demorou quase dez anos para descobrir que era doente compulsiva pelo jogo, passando a frequentar os Jogadores Anônimos¹. Seu depoimento e sua história podem ser encontrados no Portal Espaço Aberto.

Para o jogador compulsivo que não encontrar a passagem da purificação só lhe restará um caminho: viver o mito de Erisícton ou Erisictão. Rei da Tessália, rico, ímpio e violento, penetrou em um bosque consagrado a Deméter, deusa da agricultura, derrubando árvores consagradas a ela e golpeando com o machado um imenso carvalho, árvore favorita da deusa. Como castigo, foi colocada em seu estômago a fome que o fez devorar toda a comida disponível em seu palácio e gastar toda a sua fortuna, vendendo inclusive sua filha para conseguir mais comida. Erisictão, enlouquecido, não conseguindo se saciar e emagrecendo sem parar, começou a comer os próprios membros e acabou devorando a si próprio.

\title{
5 Considerações finais
}

${ }^{1}$ É um programa para ludopatas, com a finalidade de manter a abstinência em relação ao jogo e viver bem em sociedade. 
Lacan (1999), concentrando-se no estudo da angústia fundamental humana, ou seja, a falta, julga que ela é fundamentalmente preenchida por objetos metonímicos, desviando a ausência para uma possível presença, aquela que estará sempre num próximo objeto de desejo. Por isso, o ser humano é um eterno "desejante", que só não enlouquece porque é envolvido pelo jogo da cadeia significante, aquele que permite que um signo seja sempre substituído por outro signo. Assim, exemplificando, se o objeto do desejo a ser alcançado não satisfaz o primitivo desejo do ser humano, ele o ilude com a promessa de que o próximo objeto irá satisfazê-lo e, assim, ad infinitum. Esse processo de desvio da falta focalizado por Lacan é um efeito possível apenas com o auxilio das imagens euforizantes do noturno, e como o jogador vive incessantemente as imagens de luta do diurno, a sua situação existencial é a vivência apaixonada da consciência da falta e toda sua angústia. Viver esse vazio em toda a sua força é escavar o buraco cada vez mais e escancarar a falta, muito bem ilustrada pelo mito da personagem que devora a si mesmo, pois a incompletude elevada ao extremo é igual à inexistência.

Constata-se, ainda, que, num momento em que o país passa por uma crise de moralidade público-política, há parlamentares no Congresso e na Câmara que defendem a legalização dos jogos de azar. É evidente que, alegando que o país vai auferir lucros na cobrança dos impostos, eles estão a serviço dos empresários do setor, os mesmos que exploravam as casas de bingo. A permissão de cassinos, jogos de apostas online, bingos etc., além de fomentar o crime organizado, fere questões morais e de saúde pública. Não parece efetivo propor um cadastro nacional de jogadores patológicos, os "ludopatas". A legalização da atividade é mais uma maneira de atender aos interesses de poucos em detrimento da sociedade, que precisa mais do que nunca de outras ofertas: educação, saúde, cultura, segurança. Mais ainda, de bem-estar, para que se possa viver em plenitude a riqueza de um imaginário fecundo e inspirador.

\section{Referências}

A FORÇA do querer. Criação de Glória Perez. Direção de Pedro Vasconcelos. Rio de Janeiro: Central Globo de Produção, 2017. 172 episódios.

BACHELARD, G. A poética do devaneio. São Paulo: Martins Fontes, 1996.

DAMÁSIO, A. 0 mistério da consciência. São Paulo: Companhia das Letras, 2000. 
DELEUZE, G.; GUATTARI, F. 0 que é filosofia? 2. ed. São Paulo: Editora 34, 2003.

DURAND, G. Mito, símbolo e mitodologia. Lisboa: Editorial Presença, 1982.

DURAND, G. As estruturas antropológicas do imaginário. Lisboa: Editorial Presença, 1989.

DURAND, G. Campos do imaginário. Lisboa: Inst.. Piaget, 1995.

INSENSATO coração. Criação de Gilberto Braga e Ricardo Linhares. Direção de Dennis Carvalho e Vinícius Coimbra. Rio de Janeiro: Central Globo de Produção, 2011. 185 episódios.

LACAN, J. O seminário, livro 5: as formações do inconsciente. Rio de Janeiro: Jorge Zahar Editor, 1999.

MELITO, Leandro. Jogos de azar: "Você nunca vai ganhar. A palavra já diz: é um jogo", diz ex-compulsiva. [S.I.]: Portal EBC, 2016.

O QUE É jogo de azar. In: ASSOCIAÇÃO VIVER BEM. Virando o jogo: apostando na saúde e na responsabilidade. São Paulo: Associação Viver Bem, 2017.

OS VÍCIOS da sociedade de consumo. [S.I.]: Geral Fórum, 2013.

STRÔNGOLI, M. T. Do signo ao símbolo: as figurativizações do imaginário. In: PINO, D. (Org.) Semiótica: olhares. Porto Alegre: EDIPUCRS, 2000. cap. 4, p. 55-65.

SUTTON-SMITH, B. The spirit of play. In: FEIN, G.; RIVKIN, M. (Org.). Review of research. Washington: National Association for the Education of Children, 1986. v. 4, p. 3-15.

TAVARES, J. Doença do Jogo Compulsivo atinge 10\% da população de São Paulo. Espaço Aberto, São Paulo, n. 41, mar. 2004.

VÍCIO invisível. As histórias de quem perdeu tudo o que tinha no casino. Jornal I, Lisboa, 12 maio 2012.

\title{
The green cloth of illusion: imaginary and illegal gambling
}

\begin{abstract}
The language of compulsive gamblers' statements is likely to explain their symbolic relationship to the world. From this perspective, one examines the mythic images of the senses of linguistic signifiers. Through testimonies of compulsive gamblers collected on the internet, it is reflected on the anthropological path of the player's imaginary of illegal games and their myth. The theoretical assumptions of this work are based on the anthropology of the imaginary of
\end{abstract}


Gilbert Durand, according to which the relation of the subject to the object can be represented by an image. Playing with chance or odds can have the symbolic sense of trading with fate. Being able to control one's fate is possible only to the gods, the immortal beings. Therefore, the space of illegal gambling is a profane space in contact with the sphere of the sacred, which enables this illusion of playing with destiny. In this sense, the game can be seen as a mythical experience.

\section{Keywords}

Imaginary Anthropology. Myth. Regimes. Illegal Gambling.

Recebido em 03/01/2017

Aceito em 09/03/2018 